\title{
DÜBLIN
}

Technological University Dublin

ARROW@TU Dublin

\section{Employee Perspectives on the Post-integration Stage of a Micro- merger}

Jennifer Lawlor

Technological University Dublin, jennifer.lawlor@tudublin.ie

Follow this and additional works at: https://arrow.tudublin.ie/tfschhmtart

Part of the Business Administration, Management, and Operations Commons, Human Resources Management Commons, and the Organizational Behavior and Theory Commons

\section{Recommended Citation}

Lawlor, J. (2013),"Employee perspectives on the post-integration stage of a micro-merger", Personnel Review, Vol. 2 Iss 6 pp. 704 - 723. doi:10.1108/PR-06-2012-0096

This Article is brought to you for free and open access by the School of Tourism \& Hospitality Management at ARROW@TU Dublin. It has been accepted for inclusion in Articles by an authorized administrator of ARROW@TU Dublin. For more information, please contact arrow.admin@tudublin.ie, aisling.coyne@tudublin.ie, gerard.connolly@tudublin.ie.

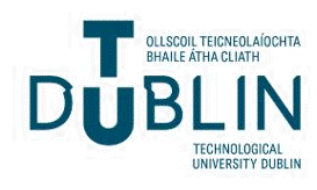


PR

42,6

704

Received 22 June 2012

Revised 3 November 2012

Accepted 15 January 2013

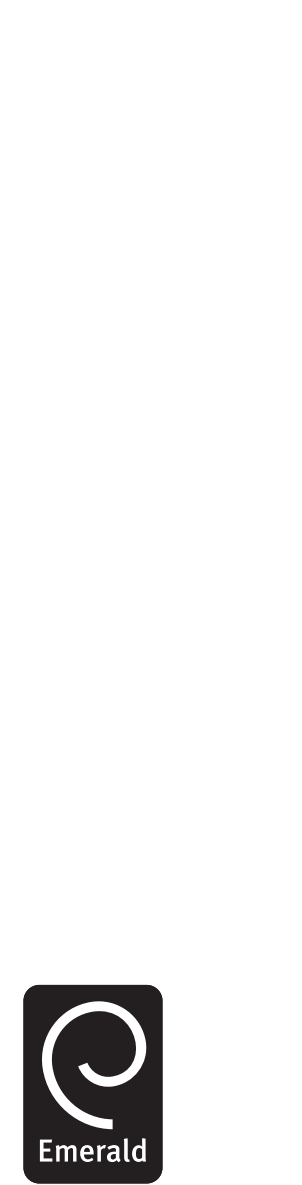

Personnel Review Vol. 42 No. 6, 2013 pp. $704-723$

(c) Emerald Group Publishing Limited 0048-3486

DOI 10.1108/PR-06-2012-0096

\section{Employee perspectives on the post-integration stage of a micro-merger}

\author{
Jennifer Lawlor \\ Dublin Institute of Technology, Dublin, Ireland
}

\begin{abstract}
Purpose - This paper seeks to address the impact of an organisational change initiative on organisational employees, with specific reference to a micro-merger which occurred in a public sector, higher education organisation in Ireland. The literature on change management is examined, with specific reference to the post-integration stage of a micro-merger. The paper then reports on a study that was undertaken in an Irish higher education institution and focuses on the impact of the micro-merger on employees. Specifically, the study seeks to address their perceptions and emotions relating to a heretofore under-researched area in the merger literature, namely the impact of a change of physical geographical location and the accompanying change of physical facilities on employee motivations and well-being.
\end{abstract}

Design/methodology/approach - The aim of the research was to examine the post-integration stage in a newly merged entity, in terms of the employees' perceptions regarding the impact of such organisational change on them, from a personal perspective. A phenomenological approach was adopted in this study. A total of 41 in-depth interviews were conducted with academic employees (i.e. lecturers) of an Irish higher education institution.

Findings - The participants had varying feelings and emotions, resulting from the practical and personal manifestations of the change wrought by the micro-merger. These emotions ranged from excitement to anxiety and apprehension. A major theme in the literature is that organisational change can be destabilising for all organisational members, resulting in uncertainty, fear, psychological stress, anxiety and insecurity. This was not the experience in this study. The merger certainly represented a significant change for the participants, but in contrast to the aforementioned stark view of mergers, the participants exhibited a more practical and pragmatic approach to this organisational change.

Originality/value - This exploration of the emotional impact of a merger on employees is noteworthy in the context of a major research gap in the literature concerning the "soft" or human resource issues arising from a merger. Specifically, the paper illustrates a heretofore under-researched aspect of the change management and post-merger literature, namely the substantial impact of a change in physical location and physical facilities on employees' motivations and sense of well-being.

Keywords Mergers, Change management, Employee impact, Post-merger situation, Qualitative

Paper type Research paper

\title{
Introduction
}

Mergers have long been viewed as a very attractive organisational strategy (Kumar and Bansal, 2008; Cartwright and Schoenberg, 2006). A review of the literature pertaining to merger activity demonstrates that a large emphasis in merger research to date has been on the financial and organisational dimensions, i.e. the so-called "hard" issues (Cartwright, 2005; Hamill, 1991; Napier, 1989). It is therefore evident that a research gap exists regarding the impact of a merger on organisational members, i.e. "soft" issues (Van Dick et al., 2006; Cartwright and Cooper, 1993a; Schweiger and DeNisi, 1991; Somers and Bird, 1990). In this respect, Cartwright and Schoenberg (2006, 
p. 3) refer to the human impact of a merger (i.e. emotions and behaviours) as being an "emergent and growing field of enquiry". However, mergers can differ in terms of size and scope. For example, when two, heretofore separate organisations, join forces as a newly merged entity in pursuance of a new strategic direction, the nature of the accompanying change tends to be substantial and transformational. In this respect, Van Dick et al. (2004, p. 122) recognise that a merger is a "tremendous process of organizational change". On the other hand, mergers can also operate at micro or smaller levels whereupon such a change initiative may involve the merging of internal functional units in the same organisation, which heretofore had been operating as separate entities. This type of initiative can therefore be referred to as a micro-merger (Kilfoil and Groenewald, 2005). This paper reports on a study that was undertaken in a higher education institution, in Ireland, following a faculty merger, which united two heretofore separate, geographically disparate halves of the faculty. This paper examines the characteristics of a merger that are applicable to a higher education context and specifically focuses on the impact of this micro-merger on employees, i.e. their perceptions and emotions arising from the merger. The paper commences by examining the literature on post-merger integration and identifying the research gaps therein. The author then proceeds to explain the research methodology underpinning this study. The findings of this study are then presented, specifically the employees' personal perspectives on the impact of the merger on them as organisational members. Finally, the paper considers the conclusions emanating from this study.

\section{Understanding the nature of change}

Although organisational change activities are occurring in both the corporate and public sectors, most change management literature has focused to date on the corporate sector. Public sector organisations are besieged with a multitude of demands to change, ranging from increased transparency of their activities, public accountability, to ensuring the delivery of value-added services, in a cost-efficient manner. This is particularly evident in higher education institutions today. Indeed, Malhan (2006) contends that such institutions worldwide are experiencing change and are operating like businesses.

In terms of defining the nature of change, Mills and Murgatroyd (1991, cited in Tiernan et al., 2001, p. 424) define change "as perceived or felt differences in circumstances and behaviour, to such an extent that a situation becomes or is made different". Coulter (2005, p. 42) defines change as "any alteration in external environmental factors or internal organizational arrangements". This stance is further supported by Nelson (2003, p. 18) who asserts that change involves "moving from the status quo to a new, desired, configuration to better match the environment". Therefore, by definition, change results in an alteration in the "status quo". One major manifestation of such change is a merger strategy.

\section{Mergers - a definition}

There is a plethora of definitions surrounding what constitutes a merger in both the corporate and public sectors. For example, Haberberg and Rieple (2001, p. 612) characterise a merger as "the creation of a new legal firm by the bringing together of two or more previously independent companies". This definition recognises that two heretofore independent companies are uniting to form a new separate legal entity.

\section{Employee perspectives}

705 
PR

42,6

706
Similarly, Coulter (2005) regards a merger in its legal context whereby two or more parties amalgamate their activities resulting in the establishment of a new entity. The development of a "new" corporate entity emphasises that the merging partners are embarking upon a fundamentally new strategic direction which will require significant organisational change on both their parts. More generally, Gill and Foulder (1978, p. 15) characterise a merger as "organisational change wherein the object of the change is to create one organisational system from two previously distinct entities". Thus, it appears that the term "merger" does not lend itself to a single or common definition. For example, Haberberg and Rieple (2001) focus on the merging of two companies into one entity. On the other hand, Coulter's use of the word "parties" is more general and all-encompassing as it could reasonably refer to the amalgamation of groupings, teams or units (Collins, 2007), and not just the amalgamation of previously separate corporate entities.

As in the corporate sector literature on mergers, there is a plethora of definitions surrounding what constitutes a merger in higher education. Just as there is no universally accepted definition of a merger in the corporate sector literature, the problem of arriving at a universally accepted definition in the higher education literature is exacerbated by the variety of activities and structures in the higher education system worldwide. However, a widely cited definition of a higher education merger is that proposed by Goedegebuure (1992) cited in Lang (2002, p. 39):

A merger in higher education is the combination of two or more separate institutions into a single new organisational entity, in which control rests with a single governing body and a single chief executive body, and whereby all assets, liabilities and responsibilities of the former institutions are transferred to the single new institution (Goedegebuure, 1992).

One of the most frequently cited reasons for pursuing such a strategy within the education sector stems from the resulting facility for economies of scale. In this regard, Norgard and Skodvin (2002) contend that the main objective for merging higher education institutions has been the creation of larger units, thus resulting in academic and administrative economies of scale. Specifically, referring to the merging of the education system in Norway, Kyvik (2002, p. 53) states that:

[...] the purpose of the reorganisation was to enhance the quality of administrative functions and academic work through the creation of larger administrative and academic units, to break down barriers between the former colleges, and to develop new and broader study programmes.

Financial factors may also play a part in explaining mergers in higher education. Lang (2002) suggests that institutions merge in order to take advantage of government incentives that reward such merger activity. This view that mergers in higher education are commonly driven on the basis of an expectation of improved financial and economic health is widely held (Curri, 2002; Kyvik, 2002; Wang, 2001; Skodvin, 1997).

Elsewhere, Skodvin (1999) offers a broader perspective on the rationale for a merger by asserting that the most recurrent motives would appear to be the achievement of administrative, economic and academic advantages. He contends that a larger merged unit will produce a strong academic institution with a more professional and streamlined administration, the elimination of duplicative programmes, and an increase in academic integration and co-operation (Skodvin, 1999). 


\section{The post-integration phase of merger activity}

Whilst the literature has placed an overwhelming emphasis on the rationale for pursuing a merger strategy (Schraeder and Self, 2003; Balmer and Dinnie, 1999), substantive discussion of post-merger organisational change processes did not really commence until the 1980s (Vaara, 2001). Consistently, there have been calls within the literature for more research to be conducted into the aftermath of a merger, in other words, how the organisation fares "post-integration" (Vaara, 2002; Napier, 1989; Kostuch et al., 1998; De Noble et al., 1988; Shrivastava, 1986). In this respect, Shrivastava (1986) contends that little analysis has been undertaken on the post-integration phase, and on the impact of a lack of integration on organisational performance. This is supported by Child et al. (1999) and Walsh (1989) who agree that there has been a lack of scrutiny regarding the post-acquisition stage. This reflects Napier's (1989) conclusion that mergers are typically poorly understood and managed, particularly in relation to human resource issues.

As referred to above, most of the existing post-merger literature concentrates on the financial performance of the newly merged entity (Cartwright and Cooper, 1995; Somers and Bird, 1990). But it has been argued that the success of the post-merger stage is equally dependent on the integration of human resources and the degree of cultural fit. What is surprising is the dearth of research addressing these two critical areas of post-merger integration. Specifically, Ivancevich et al. (1987) acknowledge that executives tend to be preoccupied with the financial and legal aspects of mergers and rarely focus on the impact of mergers on human resources.

It is therefore clear from the literature that a particular "soft" issue stands out as being ripe for further study - that of the impact of a merger on organisational members. A review of the literature would suggest that there is a distinct lack of emphasis placed on the role of human resources and the merging of, heretofore, different cultures (Marks, 1997; Cartwright and Cooper, 1995, 1993a, b). It is suggested that some analysts only pay attention to the financial or "hard" issues associated with a merger, for example, share price, tax exemptions, price/equity ratios, borrowing costs and value maximisation, to the detriment of the human or "soft" issues, for example, employee morale and job satisfaction, employee stress levels, and human behavioural and attitudinal issues.

According to Cartwright and Cooper (1993a), the human dimension to merger activity and the impact such a change has on employee health and well being has not attracted much research attention. This observation is further supported by the work of Schweiger and DeNisi (1991) and Marks (1982). The scant literature that does exist, concentrates on employees' reactions to mergers (Napier, 1989), and the reactions of managers or executives to mergers (Cannella and Hambrick, 1993; Siehl et al., 1990; Ivancevich et al., 1987; Schweiger et al., 1987; Marks and Mirvis, 1985). Vaara (2002, p. 213) contends that the overall theme emanating from these studies is that human resource issues "receive too little attention, or are under-managed, thus seriously hampering organisational integration".

The element of uncertainty for employees associated with a merger strategy has been the subject of commentary. For example, Bartels et al. (2006) refer to a "sense of continuity", which essentially refers to the "me" issues resulting from a merger process, such as "what will this merger mean for me?" and "to what degree will it involve change for me?” In this manner, employees may question whether they have to

\section{Employee perspectives}

707 
PR

42,6

708 physically move or whether their organisational role will change post-merger. Furthermore, Bartels et al. (2006) highlight different features of perceived threat, such as stress and uncertainty relating to the outcomes of the merger. In summary, a gap in the merger literature appears to prevail with regards to the impact of a merger on employees, as opposed to an emphasis being placed on the strategic orientation of the entities involved in the merger.

\section{Physical location}

A specific issue that would appear to be wholly under-researched in the literature is the impact of a change of a physical geographical location or a change of physical facilities on employees in the merged organisational entity. It may be the case that when two, heretofore independent entities form a new organisation, there could be an over-supply of some key resources, for example, physical facilities in certain geographical locations. If a proportion of the workforce of one (or both) firms relocates to fit in with the new reorganisation of the merged entity, this may have a significant impact upon their psychological well-being. This in turn may affect the integration of human resources and cultural compatibility. Yet the literature does not appear to focus at all on the physical location of the newly merged entity in the post-merger stage. Laframboise et al. (2003) contend that an employee's attitude towards an impending merger and the accompanying relocation, centres around personal issues such as one's desk-space, the disruption to one's personal effects such as pictures, and access to amenities such as cafés and parking.

Leaving aside physical location, the literature accords very little attention to the physical setting in a merger situation. In this regard, Brief and Weiss (2002) maintain that there is little research available regarding the impact of the physical setting (e.g. lighting, noise, temperature) on employee feelings. They cite a study by Wasserman et al. (2000) that utilised both quantitative and qualitative research to explain the interaction of physical organisational cues and participants' emotions. When these participants were shown photographs of "eclectically designed establishments", they exhibited pleasant emotions, but when shown "monomorphic designs", their responses were varied (Brief and Weiss, 2002, p. 291).

In view of the discussion to date, it may be inferred that a physical locational setting or physical work environment, for example, a building's facilities, offices and restaurants, may actually play an important role in facilitating change amongst employees. Indeed, the impact of the physical features of an organisation on employee satisfaction, motivation and productivity has long been recognised (Oldham and Brass, 1979). More specifically, Burke (1988) identifies the possibility of a transfer to a new location, as a result of a merger, as being one of the sources of stress and uncertainty for employees. In all, whilst some literature acknowledges the importance of the physical setting (Brief and Weiss, 2002), very little research has been carried out in this area. Therefore, a very substantial gap exists in the literature indicating how a change in the physical environment (e.g. moving to a new location) may affect organisational members.

\section{Research methodology}

This section addresses the research methodology that was employed in this study. The unit of focus in this research was a faculty within an Irish higher education institution 
that had experienced an amalgamation of two heretofore separately functioning entities. Specifically, the amalgamation involved the unification of two heretofore, geographically disparate units of the same faculty which had been operating in an overwhelmingly separate manner in terms of staff interaction, programme delivery, research activities and supervision, physical location and facilities, administration and student services.

It is necessary at this stage to substantiate the assertion that this change initiative constituted what is deemed to be a micro-merger. From a review of the literature, it is clear that there are difficulties in arriving at a universally acceptable definition of what a merger is, and its evolutionary process. There are certainly different nuances and levels of emphasis within each of the above definitions. However, Parvinen and Tikkanen (2007, p. 763) define a merger as an "organizational amalgamation that leads to two or more formally separate economic entities appearing within a single organizational boundary". In the present study, whilst the two merging entities were non-economic in nature, the merger did indeed constitute an organisational amalgamation of two formally separate entities, into one single organisational boundary, namely, one unified faculty.

Furthermore, the assertion that mergers can differ in size and scope is supported in the previously discussed definition offered by Coulter (2005) who refers to the amalgamation of the activities of two or more parties, resulting in the establishment of a new entity. As posited above, the term "party" is so general as to encompass the merging of organisations, as well as the merging of groupings, teams and units (Collins, 2007). Finally, the use of the nuanced term "micro-merger" to describe the Irish higher education institution at hand, is also supported by a previous study by Kilfoil and Groenewald (2005) who explored a merger at a micro level which incorporated the merging of two higher departments, in the context of a South African higher education institution.

Specifically, in the case of the Irish higher education institution at hand, two units of a faculty were being merged on one physical site, where heretofore, the two units had operated separately in terms of each delivering their own suite of (often complementary) programme offerings and research opportunities, resulting in duplication of teaching and research supervision, whilst also having duplicative administrative systems, e.g. examinations, management and student support systems. The motives in merging these two entities reflected those highlighted by Skodvin (1999), namely the achievement of administrative, economic and academic advantages. Furthermore, it has been suggested that a larger merged unit will produce a strong academic institution with a more professional and streamlined administration, the elimination of duplicative programmes, and an increase in academic integration and co-operation (Norgard and Skodvin, 2002; Skodvin, 1999). Again, this was the strategic reasoning underpinning the merger initiative undertaken in the Irish higher education institution under scrutiny, which brought two heretofore geographically disparate and separately operant halves of a faculty together, on one new campus. Specifically, one half of the faculty moved to the new building and were already in situ in the new campus (referred to hereafter as the "incumbents") whilst the other half moved to the campus some years later (referred to hereafter as the "movers").

This strategy led to a major streamlining of programme development and delivery, sharing of teaching and research supervision across two heretofore separately

\section{Employee perspectives}

709 
PR

42,6

710

operating entities, and also resulted in the removal of a duplicate level of programme delivery, research supervision, administration and student support services. At senior level, the Dean of the Faculty and the governing body of the institution remained in situ, further supporting the author's assertion that this change strategy constituted a micro-merger involving the amalgamation of two large but separately existing halves of the faculty, as opposed to the merging of two organisations into one new entity.

The aim of the research was to examine the post-merger stage being experienced in the merger entity, in terms of the employees' perceptions regarding the impact of the merger on them, from a personal perspective. This aim had been stimulated by a substantial gap in the literature pertaining to the impact of a merger on organisational members, as opposed to the literature's longstanding emphasis on the organisation's raison d'être for pursuing a merger strategy.

41 in-depth interviews were conducted with academic employees (i.e. lecturers) of this Irish higher education institution. A phenomenological approach was identified as best capturing the focus of this research which was to gain insights into employees' perceptions of the merger, recognising that post-merger integration might hold different realities and meanings for different employees. The research was conducted two years after the merger to reflect the post-merger integration stage. This two year time span after the merger was supported by Cartwright and Cooper (1995) who suggested that the change wrought by major organisational transition, such as a merger, can affect employees for anything between six months and four years later.

In-depth interviews were deemed to be the most appropriate research method. Goulding (2002, p. 59) favours the use of a semi-structured interview because of its potential "to generate rich and detailed accounts of the individual's experience". As such, this method was appropriate in light of the author's contention that the impact of mergers on employees has been vastly under-researched. The requirement to access rich and detailed participant insights is also evident in Carson et al.'s (2001, p. 73) observation that interviews lend themselves to uncovering "feelings, memories and interpretations that we cannot observe or discover in other ways".

Specifically, a semi-structured interview approach was utilised whereby participants were invited to discuss their views as to why the merger occurred, their expectations about the merger, and changes arising from the merger. The author conducted all interviews and gained access to the sample by virtue of being a fellow lecturer in the same institution. However, the author was not known, in the main, to the participants. This was a feature of the author being a lecturer in a different discipline, in a wholly separate faculty, and different geographical location, in the institution. The author was cognisant of the potentially sensitive nature of this research as participants were being invited to discuss in detail their working environment and all of the corresponding constituent elements that comprise this environment. To this end, ethical parameters were strictly observed in terms of guaranteeing the participants' anonymity and confidentiality (Hussey and Hussey, 1997). Whilst all participants were lecturers involved in teaching and research, they are not referred to in the discussion below by their discipline, age or gender. This was a feature of some participants indicating that they wished for complete anonymity if they were to offer frank and detailed views on their colleagues and their place of employment, in the post-merger context. Therefore, participants below are referred to only in relation to their "mover" or "incumbent" status. The interviews were transcribed and the data then manually 
analysed by coding and categorising the data, and subsequently identifying patterns in the data with a view to identifying key themes or relationships. The author chose to manually analyse the data rather than use a qualitative computer software programme, for example, NVivo, in keeping with Carson et al.'s (2001) assertion that manual analysis lends itself to a deeper appreciation of the multiple meanings that may be derived from qualitative data.

\section{The impact of the merger - a personal perspective}

Overall, the participants were interested in and engaged by this research and were very vocal in their contributions regarding how the merger impacted upon them. It was clear that the physical locational merger, as well as the merging of heretofore separate systems of programme delivery, administration, research supervision and student support systems, evoked a range of personal emotions and feelings in participants. Academic staff in the old location (the "movers") had worked for years in sub-standard accommodation and facilities. For example, the building itself comprised a number of Georgian terraced houses that had not been designed with an educational function in mind. On the other hand, those staff already in situ (i.e. the incumbents) viewed their new colleagues (the movers) with a certain sense of trepidation tinged with nervous welcome. Thus, both positive and negative emotions were expressed, namely, sadness and nostalgia, anxiety and apprehension, and satisfaction. Employees' positive emotions were driven by the location of the merged faculty, the new building and the enhanced academic environment. Negative emotions were driven largely by a sense of regret (mostly exhibited by the movers) at leaving a familiar regime and a certain sense of trepidation regarding the change being generated by the merger.

\section{Sadness and nostalgia for the pre-merger status}

Some "mover" participants had feelings of sadness leaving their old location where they had enjoyed many happy and productive years, despite the substandard accommodation there. For example, in one interview, a participant acknowledged:

[...] a sense of sadness about leaving what I was familiar with [...] a small environment where everybody was kind of thrown together quite closely [...] and realising that the whole environment was going to be greatly expanded (Mover 3).

Inherently linked with this feeling of sadness is a sense of nostalgia where the participant appeared to be somewhat mournful for an environment that offered an element of familiarity: "almost a bit of sentimentality then about leaving a really badly cramped building [...] leaving what I was familiar with" (Mover 3).

Another participant highlighted a mindset about innovation in the faculty. It was observed that people had become so used to undertaking their roles and responsibilities in a certain way that changing these habits and mindsets may be rather difficult for them, for example:

I think there is a large section [of organisational members] [...] that would not naturally have been innovative, and they would have done things in a particular way and it's not natural for them to move away from that, and that they struggle a little bit in moving away from the [...] norm, or the traditional thing, and I think it's quite a large section that has that issue (Mover 6).

\section{Employee perspectives}

711 
PR

42,6

712

\section{Anxiety and apprehension}

Another emotion that was identified was a level of anxiety whereby a large number of participants, particularly those moving to the new location were worried about the allocation and type of office accommodation they would receive in the new campus. Equally so, the incumbent participants were also worried about the allocation of office space, as one participant described:

There was a lot of concern I know amongst the population about [...] moving offices, we're going to be moved here, we're going to be moved there, to me it didn't really matter. I was sort of very much at the stage where I was open to wherever I'd be moved [...] I figured it would be a new experience if I was moved in with a new cohort of people (Incumbent 13).

This participant was obviously very open to the new office allocation and indeed re-allocation process. However, some participants were apprehensive at being moved away from their existing familiar office arrangements, as the following excerpt identifies:

[...] people were saying that what they might do to assist the merger is to have some people [movers] and some people [incumbents] in the one office and I think that was sort of sent around as a rumour which again didn't concern me, but a lot of people wanted to stay with their own colleagues or their own [discipline] areas (Incumbent 13).

Therein, the participant draws attention to the potential for pre-merger rumours to prevail in such a change initiative, but also alludes to his own response in discounting such rumours and not allowing them to affect him. His perspective is also redolent of an "us versus them" mentality in that some lecturers wished to remain in their existing office groupings as opposed to being given new office accommodation with new colleagues. This reflects Bartels et al.'s (2006) view that following a merger, organisational employees or what they call the "mergees", may feel under threat when their group is in danger of extinction by the "infusion" of new personalities, thereby ensuring that they stick tightly to the group with which they are already familiar. In this manner, a social aspect to organisational membership is recognised.

Equally another incumbent reflected that nostalgia for "the way things were" (pre-merger) could also be explained by a familiarity with the former status quo and a certain trepidation towards change. This participant (Incumbent 27) recognised that people are creatures of habit, and any changes in habit pose a serious upheaval for staff, for example:

[...] people are creatures of habit you know, creatures of routine, they have to change offices, they have to change [...] you're uprooting what you've been, changing what you've been doing for years and years and years and the next thing you change, you've a new office [...] a new computer, car parks, location and traffic [...] it's a massive change (Incumbent 27).

However, most participants were keen to stay with their own cohort of colleagues, which normally manifested itself by virtue of the school or discipline that they were affiliated to, for example, one participant stated that:

[. . . ] my only preference at the time was that I would be with people of a similar discipline [...] I also felt that I wanted to be housed in my school [...] that was an important thing for me at the time $[. .$.$] that was just me wanting a bit of security [...] wanting to be secure around my$ school and there was another part of me though that was excited about you meeting all these other schools and embracing that as well (Mover 3). 
From the above, many of the participants, both movers and incumbents, placed strong emphasis on their familiarity with their current office allocation and the colleagues with whom they shared their office. This familiarity provided an element of security or a comfort zone to them. Therefore, any change in the status quo, for example, moving into a new building, was viewed at one level, as being somewhat threatening or a source of concern, and at another level, as being an exciting event. This concern to remain in familiar settings and/or with familiar colleagues, is reflective of social identity theory which posits that members of a group may feel threatened if that group's structure is challenged (Bartels et al., 2006). As such, the author's observation that a number of participants were concerned about the dissolution of their existing office arrangements to facilitate the merger, was strongly reflective of social identity theory. The author contends that the participants who expressed a concern regarding their office accommodation, were in fact alluding to their sense of identity that they had built over a period of time, resulting from their membership of, and familiarity with, a certain social group, namely their office colleagues.

\section{Satisfaction}

Another prevailing emotion, displayed more so amongst the movers than the incumbents, was that of satisfaction and excitement. Satisfaction levels amongst participants were categorised according to broad themes emerging in this study, namely satisfaction due to the new geographic location, satisfaction due to their perception of the new building, and satisfaction due to the enhanced academic environment.

Satisfaction - new geographic location. A key theme regarding the impact of the merger on employees' perceptions was in relation to the faculty's new geographic location and the resulting impact that the new location had on participants' travelling time to and from work. This was specifically an issue for all of the "mover" academic staff. There were mixed responses in relation to this theme, ranging from those who were annoyed at having to travel for longer periods of time to work, to those who had to travel further distances but did not mind doing so, to those who resided very near to the new location and whose journey times were reduced considerably.

A number of participants expressed their irritation at being moved to a new geographic location, for example: "[...] being very selfish initially I thought it was just inconvenient, it just was forcing me to trek further across the city to get to work" (Mover 1). One participant developed upon this point and stated that "initially the only concern I had was moving probably two miles away from where I lived to get to work" (Mover 3). Another participant stated that:

[...] from a very personal perspective [...] it was a bit of an issue for me that I now have to drive across [...] the city [...] adding on minimum an hour to my working day [...] half an hour in the morning and half an hour in the evening (Mover 9).

It was also evident from other participants that the proximity of their new location to their homes was not an important issue. For example, one participant asserted that where he worked "didn't make any difference [...] my commute hasn't changed a whole range” (Mover 17).

One participant referred to the fact that the new geographic location was ideal given her own home location and her proximity to direct transport links, for example: "[the] 
PR

42,6

714

geographic location is ideal for me [...] it is about the best location I could have wished for" (Mover 6). A sub-theme in these discussions was the mode of transportation that participants used to get to and from work. Some participants asserted that they enjoyed walking to work. For example, one participant stated that it was "good for me, I walk to work" (Mover 32). Other participants declared that it was now a pleasure to commute to work in better and certainly more salubrious geographic surroundings, for example: "I was quite happy to move out [of the old building] [... . because it wasn't a pleasant place to be. Not a great part of town [...]" (Mover 37).

For a large number of participants who had made the move, an important issue that arose was whether or not there would be a plentiful supply of car parking spaces in the new building. For example, one participant stated:

[.. .] I get up earlier in the morning and so I miss most of the traffic. I get a parking place every day [...] it's more generous here, there's more people, I don't know how it happens [...] there are more spaces available, you can even come at nine o'clock and still get a spot (Mover 1).

The above discussion emphasises the importance of proximity to work for most of the participants. It is clear that physical relocation exercised people's emotions in many different ways, from irritation and annoyance to satisfaction and contentment. This was one issue that really impacted upon participants immediately in the post-locational merger phase. It is arguably the first practical and personal manifestation of change and perhaps it forewarned these participants of further change and adaptation in the future. These findings further underpin the participants' self-orientation with regard to the faculty merger, i.e. they illustrate the question alluded to by Bartels et al. (2006) "what will this merger mean for me?" and "to what degree will it involve change for me?"

It is interesting to observe that the emotions expressed by the participants highlight the substantial change that the merger brought for employees. In other words, it is necessary to simultaneously consider how the merger affected their behaviour and feelings. For example, some participants referred to longer travelling times which in turn led to feelings of irritation and annoyance. However, the participants also expressed satisfaction arising from the new building, which will be outlined below.

Satisfaction - perception of new building. Many of the "mover" participants were very happy with their new location and compared it with their previous facilities, indicating that their previous building and associated facilities had been sub-standard and crowded. This is evident from the following quotes:

[...] the building was so small, you certainly met people an awful lot more and there was just one small staffroom where you had your coffee or your lunch (Mover 1).

I think in the other place we used to get depressed [...] I didn't realise how depressing the whole area [...] really was to work in until I [...] walked into this beautiful new place [...] you had people coming from almost a tenement type building into a purpose built building (Mover $3)$.

[...] some of the rooms in [the old building] were just truly appalling and [...] there was huge problems with ventilation [...] you were often at considerable disability carrying out a class and that $[\ldots]$ operationally was problematic (Mover 4).

[...] [the old building] is an awful place, both its location isn't ideal, and the building itself is about as far removed from state-of-the-art as you're [...] likely to find (Mover 9). 
Given these sentiments regarding the old building and facilities in which the movers had been housed, it could be reasonably assumed that the participants would welcome a move to a purpose-built new campus, as evidenced by the following excerpts:

[...] facilities here are much, much better, I mean, hundreds of times better (Mover 2).

[...] there is more lecture-student interaction [...] it's so open-plan, there's a lot of space [...] when I was in [the old building] it had so many corridors [...] it was all over the place [...] it was like a maze so you know you wouldn't really bump into students at all whereas here they're all hanging out (Mover 18).

As mentioned above, whilst the majority of participants did indeed welcome the new purpose built campus, one of the outcomes of the new building was the fact that some participants found it somewhat big and anonymous. For example, one participant identified that "I like the building, I like everything about it, the only thing I don't like [...] is that it's so big, it's anonymous" (Mover 1). This was a recurring theme throughout the interviews and one participant even likened the new purpose-built campus to that of a "shopping center" (Mover 10).

It was also observed that some of the participants felt that the size of the building exacerbated the perceived loneliness of the lecturing role. For example, one participant highlighted the fact that lecturing was "a lonely enough environment and I felt that I was moving into a lonelier environment" (Mover 3). This theme was reflected in the fact that another participant asserted that "you are your own boss" (Mover 29) and that lecturers had a certain degree of autonomy in the context of the frequently individualistic profession that is lecturing.

An interesting observation was made by a participant in relation to any potential negative views on integration and the physical building:

[...] people who are not happy with the integration and it's not a topic for discussion that you'd hear much about anymore [... ] it's down to personalities [.. . ]it's certainly is nothing to do with the physical structure within the place (Incumbent 8).

It is interesting to note however that some participants preferred the anonymity afforded to them in the new purpose-built campus. One participant felt that the atmosphere in the old building had been a bit too intimate and likened the building to a "fishbowl location" (Mover 16). This theme of intimacy in the old building was further identified by many participants, for example: "it was small, it was very intimate and you got to know everyone really well” (Mover 17).

Interestingly, the participants, in the main, perceived the size of the new building from a purely personal perspective. However, one participant referred to the perspective of another party - the student. This outlier theme emanated from one participant who mentioned that perhaps the building could also be perceived as being big, anonymous and lonely by the student population. This may be evidenced by the following excerpt:

[...] it would be awful to be [...] a student and you didn't immediately gel with a group of students or make friends or whatever, it might be a lonely building (Mover 2).

Satisfaction - enhanced academic environment. A significant theme to emerge from this study was the extent to which the new physical location would result in an

\section{Employee perspectives}


PR

42,6

716

increasingly integrated academic environment. One participant felt that the new location made people feel more positive and focused in their work, for example:

I think everyone feels better about themselves [...] I think everyone feels that this is much more of a college, a university type [...] we feel more confident [...] I think we behave as better academics. I think we are doing more research, we are doing more writing [...] we are contributing more positively to Irish academia (Mover 17).

This theme was further supported by the view that with the new physical location there was a stronger sense of identity within the faculty, for example: "there is a stronger sense of being a part of the faculty [...] as opposed to being a part of the school" (Mover 18). Academic integration was also enhanced through the development of informal research groups, syndicate groups or special interest groups (SIGs). One participant referred to the fact that since the merger "there's been lots of syndicate groups set up and people seem [...] to really value that" (Mover 18).

A further sub-theme emerged in the context of a more formal work environment, namely, that some participants felt their new working life arising from the merger, was more enjoyable and stress-free. One "mover" participant believed that "people look happier" in the newly merged campus and "they look better" (Mover 2). Another participant suggested that the merger had been a "very uplifting, very motivating" experience and that "the whole environment is bright" (Mover 3). This was further supported by a participant who described his working life as being "so much more enjoyable and stress free" (Mover 4).

There was a strong understanding of the need to progress in the new academic environment. Participants referred to their excitement at the new opportunities that were being created by the merger, such as the development of new academic posts and enhanced career development. This may be evidenced by the following excerpts:

I was excited about changes at the same time [... . I felt you know an injection of new culture [...] a time for us to change (Mover 3).

It does the world of good to [...] accept change and see it for the good points rather than the bad points (Mover 12).

I think career development has opened up quite significantly for a lot of people [... . to grow and develop (Incumbent 34).

Overall, all participants recognised the need to progress in their new academic environment, as one participant succinctly opined: "life goes on. Let's live in the future rather than revel in times gone past” (Mover 38).

\section{Discussion of findings}

Whilst the extant literature has exhaustively examined the financial and organisational rationale and outcomes of merger strategy, very little research has focused on the softer, people issues specifically relating to how a merger affects its organisational members (Vaara, 2002; Cartwright and Cooper, 1993a). In the present study, the participants had varying feelings and emotions, which tended to result from the practical and personal manifestations of the change wrought by the merger. For example, the location of the newly merged faculty suited some and not others. Equally, some participants favoured the large building because of its anonymity whilst others regarded this as a drawback. All of the participants made strong reference to the "me" 
issues in terms of how the location was for example, convenient in terms of travelling distance and time. The overall findings regarding the emotional outcomes of the merger address a major research gap in the literature concerning the impact of a merger specifically on employees. For example, Vaara (2002) contends that such human resource issues have received too little attention whilst Cartwright and Cooper (1993a) similarly highlight the need for more research on a merger's impact on employee health and well-being.

More specifically, the author addressed a clear gap in the literature in terms of an apparent lack of research pertaining to the post-merger situation in a higher education context, and the resultant impact that the new physical location, building and facilities had on organisational members. It is evident from the extant literature that significant emphasis has tended to be placed on the business and financial environments resulting from a merger. However, it was evident from this research that the impact of the physical environment on employees' perceptions and attitudes was clearly a significant issue for participants.

Throughout the interviews, the participants directed the flow of discussion towards that of physical integration. They continuously referred to, in clear and succinct fashion, the "before" and "after" physical environments and associated facilities in their old faculty buildings and the new purpose-built campus. It was abundantly clear from the "mover" participants that they were glad to have moved from their "old" site, but not without a touch of nostalgia. Whether they liked it or not, this building had housed them for a very long time period, during which they taught, researched and socialised, and where they had made friends and professional work contacts. Their poor physical environment had certainly not stopped them in carrying out their roles and responsibilities.

A major finding in this research concludes that the "new" purpose-built physical environment appeared to be a significant motivator for employees and an important source of job satisfaction, but more so for the movers who were enjoying the newer facilities. This was particularly evident from the "mover" participants who identified a very apparent and welcome change in their physical working environment. As previously identified, in describing their new environment, participants inevitably referred to their old environment and consistently compared the old environment with the new environment. Equally so, the majority of the incumbent participants who had already been in residence in the new building, in the main, articulated their satisfaction with their working environment. A further significant theme also arose in relation to the provision of office accommodation in the newly merged campus. People were somewhat fearful about the move in terms of office accommodation. Furthermore, there was apprehension over whether they would get to share with their friends, the location of their office in the new building and whether they would be sharing with a person from their discipline.

This points to the concept of territoriality which constitutes an under-researched area in the literature. It has been observed in the literature that a change in physical environment may disturb or threaten employees who heretofore had marked out and defended their own territory (Brown et al., 2005). For example, employees may be very territorial over their specific organisational roles, their relationships with colleagues, their physical work environment and indeed in terms of placing family photographs and other personal belongings on their desks. One form of territoriality was very

\section{Employee perspectives}

717 
PR

42,6

718 evident in this research, in terms of the politics involved in the allocation of office space. For example, some of the participants exhibited an element of fear and anxiety regarding the type of office they would be allocated and the colleagues with whom they would have to share this space. This finding supports that of Brown et al. (2005) who contend that when a merger disturbs employees' territories, they often seek to re-define their territorial parameters. A related concept is that of psychological ownership, referring to an individual's feelings of possessiveness and attachment for an object (Brown et al., 2005). It could be argued that some of the participants exhibited psychological ownership in terms of their stated attachment towards some colleagues, in terms of shared office space. Furthermore, this perceived need amongst some movers to maintain the status quo in terms of moving to the new location and continuing to share with the same office colleagues is reflective of social identity theory. For example, Tajfel (1978) highlighted the importance of an individual's membership of a social group. Bartels et al. (2006) further identified that employees may resist a merger if they fear that it poses a threat to their existing group structure or values. This was the case in this research for those movers who strongly wished to remain in the comfort zone that was for them, sharing an office with familiar colleagues.

The literature on mergers recognises that the merger experience can often be a threat to employees' equilibrium, for example, their relationships, norms and status levels (Marks, 1982). That mergers can affect employees, in a negative manner, both psychologically and emotionally, is widely recognised in the literature (Macri et al., 2002; Davy et al., 1988). This research presents a starkly contrasting finding in that the movers and incumbents were positive about the impact of the merger on them, in an area that directly affected them, i.e. the physical work environment. That a merger can result in such positive emotional outcomes, is an area that has received sparse attention in the literature. Certainly the merger represented a significant change for the participants, but in contrast to the afore-mentioned stark view of mergers, the participants exhibited a more practical and pragmatic approach. Given the nature of this higher education institution located with the Irish public sector, it must be acknowledged that whilst job losses were not a significant factor for most of the organisational members, the associated outcomes of a merger such as the need for redeployment, up-skilling and re-location, were critical issues for their consideration.

Overall, there was general agreement that people appeared to have adjusted well to the new physical environment. In the overall scheme of academia, physical infrastructure is but one ingredient in the successful provision and delivery of an academic experience. Nevertheless, for these participants, their physical environment and indeed proximity to non-academic facilities such as the commercial district of the city, a major city centre park, banks and shops, highlights the impact of the environment on their hopes, apprehensions, aspirations and overall work practices before and after the merger.

\section{Conclusion and recommendations for future research}

This paper presented findings from a study that was undertaken in a higher education institution, arising from a faculty merger. The study specifically focused on the impact of the micro-merger on employees, i.e. their perceptions and understanding of the merger, and how it affected them. The paper commenced by examining the literature 
on merger activity, with specific reference to the rationale for pursuing a merger and post-merger integration. Furthermore, the author teased out the various perspectives that different authors offer, when defining the nature of a merger, and concluded that mergers may assume different guises in terms of their scope and scale. Accordingly, the case was made that the merger in the present study constituted a micro-merger, in that it involved the integration and amalgamation of two halves of the same faculty, which had hitherto, been operating as geographically disparate and individual entities.

In terms of adding to the body of knowledge pertaining to merger activity, this paper's contributions are two-fold. First, the author sought to address a gap in the literature pertaining to the human issues arising from a merger. This research addressed the gap by examining the personal, emotional impact of a merger on the participating organisational members, with specific reference to the impact of a change in physical environment and facilities. As such, employees placed significant emphasis on the personal outcomes of the merger or the so-called "me" issues in contrast to the literature's emphasis on the organisational outcomes of the merger. The importance of focusing on such people issues is highlighted by Van Dick et al. (2006) and Marks (1997) who argue that the human element of merger strategies tends to receive insufficient attention.

Finally, in terms of presenting an agenda for further research in this area, the author contends that there remains a major gap in the literature concerning the aftermath of a merger, from an organisational members' perspective. The literature to date has prioritised the expected utility of a merger from an organisational, strategic perspective. In other words, what are the anticipated outcomes for the organisation? From the author's perspective, a further question arises in the context of organisational members' views on post-merger integration. Future research might adopt a longitudinal perspective, by selecting an organisation that is experiencing the post-merger stage, and by returning to the participants at repeated intervals in time, to assess whether, and to what extent, integration is progressing. In terms of a smooth merger transition, how does senior management "keep employees on-board" before, during and after the merger process? A key recommendation is that senior management need to be alert to, and to be seen to be alert to, the softer, human issues that can arise post-merger. For example, the presence of a change agent may serve to assure employees that they have a voice in the organisation and a way of airing their concerns. It is therefore important that senior management are seen to be consulting with organisational members and not just communicating the organisational position to them. Napier's (1989) contention that mergers are typically poorly understood and managed, particularly in relation to human resource issues, was referred to previously. Arising from this study, it is argued that where employees feel that they are an important part of an organisation, they are more likely to respond productively to the change that is wrought by the pre, during, and post stages of a merger.

A further research recommendation is that more emphasis be placed on the issue of territoriality in organisations. In this research, it was seen to exert an impact, particularly in terms of the politics involved in the allocation of office space. Brown et al. (2005) recognise that employees tend to "mark" and "defend" their territories, but a merger may disturb such territories, thus compelling organisational members to redefine their territorial parameters and identities. Further research could be

\section{Employee perspectives}

719 
PR

42,6

720

undertaken by organisations to identify the ways in which territoriality can manifest itself, and the extent to which it should be facilitated or managed.

Finally, it is imperative that scholarly debate is re-ignited in terms of teasing out the nuanced nature and scope of different mergers. There is a tendency in the literature to view mergers as being the integration of two separate legal and commercial entities into one new entity. This paper has illustrated a small body of literature (Coulter, 2005; Kilfoil and Groenewald, 2005) to support the assertion that mergers can operate at smaller or micro levels, involving the amalgamation of two or more groupings, teams or units, which may also fall under the umbrella of the same organisation. The author therefore suggests that further consideration is given in subsequent studies to the facility for different types of mergers to occur, ranging from the widely accepted conceptualisation of two organisations coming together, to the far less researched and nascent nature of another form of merger, namely the micro-merger, which in the case of this study, involved the fusing of two separately existing but complementary units within the same organisation.

\section{References}

Balmer, J.M.T. and Dinnie, K. (1999), "Merger madness: the final coup de grace", Journal of General Management, Vol. 24 No. 4, pp. 53-70.

Bartels, J., Douwes, R., de Jong, M. and Pruyn, A. (2006), "Organisational identification during a merger: determinants of employees' expected identification with the new organisation", British Journal of Management, Vol. 17, pp. 49-67.

Brief, A.P. and Weiss, H.M. (2002), "Organizational behavior: affect in the workplace", Annual Review of Psychology, Vol. 53 No. 1, pp. 279-307.

Brown, G., Lawrence, T.B. and Robinson, S.L. (2005), "Territoriality in organisations”, Academv of Management Review, Vol. 30 No. 3, pp. 577-594.

Burke, R.J. (1988), "Managing the human side of mergers and acquisitions", Business Quarterly, Vol. 52 No. 3, pp. 18-23.

Cannella, A.A. Jr and Hambrick, D.C. (1993), "Effects of executive departures on the performance of acquired firms", Strategic Management Iournal, Vol. 14, Special issue, pp. 137-152.

Carson, D., Gilmore, A., Perry, C. and Gronhaug, K. (2001), Qualitative Marketing Research, Sage, London.

Cartwright, S. (2005), "Mergers and acquisitions: an update and appraisal", in Hodgkinson, G.P. and Ford, J.K. (Eds), International Review of Industrial and Organisational Psvchologv, Vol. 20, Wiley, Chicester, pp. 1-38.

Cartwright, S. and Cooper, C.L. (1993a), "The psychological impact of merger and acquisition on the individual: a study of building society managers", Human Relations, Vol. 46 No. 3, pp. 327-347.

Cartwright, S. and Cooper, C.L. (1993b), "The role of culture compatibility in successful organizational marriage", Academy of Management Executive, Vol. 7 No. 2, pp. 57-70.

Cartwright, S. and Cooper, C.L. (1995), “Organisational marriage: 'hard' versus 'soft' issues?”, Personnel Review, Vol. 24 No. 3, pp. 32-42.

Cartwright, S. and Schoenberg, R. (2006), "Thirty years of mergers and acquisitions research: recent advances and future opportunities", British Journal of Management, Vol. 17, pp. 1-5. 
Child, J., Pitkethly, R. and Faulkner, D. (1999), "Changes in management practice and the post-acquisition performance achieved by direct investors in the UK", British Journal of Management, Vol. 10, pp. 185-198.

Collins (2007), Collins English Dictionary and Thesaurus, HarperCollins Publishers, London.

Coulter, M. (2005), Strategic Management in Action, 3rd ed., Pearson Prentice Hall, Upper Saddle River, NJ.

Curri, G. (2002), "Reality versus perception: restructuring tertiary education and institutional organisational change - a case study", Higher Education, Vol. 44, pp. 133-151.

Davy, J.A., Kinicki, A., Kilroy, J. and Scheck, C. (1988), “After the merger: dealing with people's uncertainty”, Training \& Development Journal, November, pp. 57-61.

De Noble, A.F., Gustafson, L.T. and Hergert, M. (1988), "Planning for post-merger integration eight lessons for merger success", Long Range Planning, Vol. 21 No. 4, pp. 82-85.

Gill, J. and Foulder, I. (1978), "Managing a merger: the acquisition and the aftermath", Personnel Management, Vol. 10, pp. 14-17.

Goedegebuure, L.C.D. (1992), Mergers in Higher Education, Centre for Higher Education Policy Studies, Utrecht, in Lang, D.W. (2002), "There are mergers, and there are mergers: the forms of inter-institutional combination", Higher Education and Policy, Vol. 14 No. 1, pp. 11-50.

Goulding, C. (2002), Grounded Theory: A Practical Guide for Management, Business and Market Researchers, Sage, London.

Haberberg, A. and Rieple, A. (2001), The Strategic Management of Organisations, Prentice Hall, Upper Saddle River, NJ.

Hamill, J. (1991), "Strategic restructuring through international acquisitions and divestments", Journal of General Management, Vol. 17 No. 1, pp. 27-44.

Hussey, J. and Hussey, R. (1997), Business Research: A Practical Guide for Undergraduate and Postgraduate Students, Macmillan Business, London.

Ivancevich, J., Schweiger, D. and Power, F. (1987), "Strategies for managing human resources during mergers and acquisitions", Human Resource Planning, Vol. 10 No. 1, pp. 19-35.

Kilfoil, W.R. and Groenewald, T. (2005), "Mergers and change management at the micro level: a case study", SA Journal of Human Resource Management, Vol. 3 No. 2, pp. 11-18.

Kostuch, K.A., Malchione, R.M. and Martén, I. (1998), "Post-merger integration: creating or destroying value?”, Corporate Board, Vol. 19 No. 108, pp. 7-10.

Kumar, S. and Bansal, L.K. (2008), "The impact of mergers and acquisitions on corporate performance in India”, Management Decision, Vol. 46 No. 10, pp. 1531-1543.

Kyvik, S. (2002), "The merger of non-university colleges in Norway", Higher Education, Vol. 44 No. 1, pp. 53-72.

Laframboise, D., Nelson, R.L. and Schmaltz, J. (2003), "Managing resistance to change in workplace accommodation projects", Iournal of Facilities Management, Vol. 1 No. 4, pp. 306-321.

Lang, D.W. (2002), "There are mergers, and there are mergers: the forms of inter-institutional combination", Higher Education Management and Policy, Vol. 14 No. 1, pp. 11-50.

Macri, D.M., Tagliaventi, M.R. and Bertolotti, F. (2002), “A grounded theory for resistance to change in a small organization", Journal of Organisational Change Management, Vol. 15 No. 3, pp. 292-310.

Malhan, I.V. (2006), "Developing corporate culture in the Indian university libraries, problems and challenges of change management", Library Management, Vol. 27 Nos 6/7, pp. 486-493. 
PR

42,6

722

Marks, M.L. (1982), "Merging human resources: a review of current research", Mergers and Acquisitions, Summer, pp. 38-44.

Marks, M.L. (1997), "Consulting in mergers and acquisitions, interventions spawned by recent trends", Iournal of Organisational Change Management, Vol. 10 No. 3, pp. 267-279.

Marks, M.L. and Mirvis, P.H. (1985), "Merger syndrome: stress and uncertainty", Mergers and Acquisitions, Vol. 20 No. 2, pp. 50-55.

Mills, A. and Murgatroyd, S. (1991), Organisational Rules, Prentice Hall, London, in Tiernan, S.D., Morley, M.J., Foley, E. (2001), Modern Management: Theory and Practice for Irish Students, 2nd ed., Gill and Macmillan, Dublin.

Napier, N.K. (1989), "Mergers and acquisitions, human resource issues and outcomes: a review and suggested typology”, Journal of Management Studies, Vol. 3, pp. 271-289.

Nelson, L. (2003), “A case study in organisational change: implications for theory”, The Learning Organisation, Vol. 10 No. 1, pp. 18-30.

Norgard, J.D. and Skodvin, O.-J. (2002), "The importance of geography and culture in mergers: a Norwegian institutional case study", Higher Education, Vol. 44 No. 1, pp. 73-90.

Oldham, G.R. and Brass, D.J. (1979), "Employee reactions to an open-plan office: a naturally occurring quasi-experiment”, Administrative Science Quarterlv, Vol. 24 No. 2, pp. 267-284.

Parvinen, P. and Tikkanen, H. (2007), "Incentive asymmetries in the merger and acquisitions process", Lournal of Management Studies, Vol. 44 No. 5, pp. 759-787.

Schraeder, M. and Self, D.R. (2003), "Enhancing the success of mergers and acquisitions: an organisational culture perspective”, Management Decision, Vol. 41 No. 5, pp. 511-522.

Schweiger, D.M. and DeNisi, A.S. (1991), “Communication with employees following a merger: a longitudinal field experiment”, Academy of Management Iournal, Vol. 34 No. 1, pp. 110-135.

Schweiger, D.M., Ivancevich, J.M. and Power, F.R. (1987), "Executive actions for managing human resources before and after acquisition", Academv of Management Executive, Vol. 1 No. 2, pp. 127-138.

Shrivastava, P. (1986), "Postmerger integration”, Lournal of Business Strategy, Vol. 7, pp. 65-76.

Siehl, C., Smith, D. and Omura, A. (1990), "After the merger: should executives stay or go?”, Academy of Management Executive, Vol. 4 No. 1, pp. 50-60.

Skodvin, O.-J. (1997), "The reorganisation of non-university higher education in Norway: problems and potentials", Tertiary Education and Management, Vol. 3 No. 4, pp. 317-325.

Skodvin, O.-J. (1999), "Mergers in higher education - success or failure?", Tertiary Education and Management, Vol. 5 No. 1, pp. 65-80.

Somers, M.J. and Bird, K. (1990), "Managing the transition phase of mergers", Lournal of Managerial Psychology, Vol. 5 No. 4, pp. 38-42.

Tajfel, H. (1978), Differentiation Between Social Groups: Studies in the Social Psychology of Intergroup Relations, Academic Press, London, in Van Dick, R., Ullrich, J., Tissington, P.A. (2006), "Working under a black cloud: how to sustain organisational identification after a merger", British Journal of Management, Vol. 17, pp. 69-79.

Tiernan, S.D., Morley, M.J. and Foley, E. (2001), Modern Management: Theory and Practice for Irish Students, 2nd ed., Gill and Macmillan, Dublin.

Vaara, E. (2001), "Role-bound actors in corporate combinations: a sociopolitical perspective on post-merger change processes”, Scandinavian Iournal of Management, Vol. 17, pp. 481-509.

Vaara, E. (2002), "On the discursive construction of success/failure in narratives of post-merger integration”, Organisation Studies, Vol. 23 No. 2, pp. 211-248. 
Van Dick, R., Ullrich, J. and Tissington, P.A. (2006), "Working under a black cloud: how to sustain organisational identification after a merger", British Journal of Management, Vol. 17, pp. 69-79.

\title{
Employee perspectives
}

Van Dick, R., Wagner, U. and Lemmer, G. (2004), "Research note: the winds of change - multiple identifications in the case of organizational mergers", European Iournal of Work and Organizational Psychologv, Vol. 13 No. 2, pp. 121-138.

Walsh, J.P. (1989), "Doing a deal: merger and acquisition negotiations and their impact upon target company top management turnover", Strategic Management Iournal, Vol. 10, pp. 307-322.

Wang, X. (2001), "A policy analysis of the financing of higher education in China: two decades reviewed", Iournal of Higher Education Policy and Management, Vol. 23, November, pp. 205-217.

Wasserman, V., Rafaeli, A. and Kluger, A.N. (2000), "Aesthetic symbols as emotional cues”, in Fineman, S. (Ed.), Emotion in Organizations, 2nd ed., Sage, London, in Brief, A.P., Weiss, H.M. (2002), "Organizational behavior: affect in the workplace", Annual Review Psychology, Vol. 53, pp. 279-307.

\section{Further reading}

Bayenet, B., Feola, C. and Tavernier, M. (2000), "Strategic management of universities: evaluation policy and policy evaluation”, Higher Education Management, Vol. 12 No. 2, pp. 65-80.

Harman, K. and Meek, V.L. (2002), "Introduction to special issue: merger revisited: international perspectives on mergers in higher education", Higher Education, Vol. 44 No. 1, pp. 1-4.

Marks, M.L. and Mirvis, P.H. (1986), "The merger syndrome”, Psychology Today, Vol. 20 No. 10, pp. 36-42.

Marvin, S. and Bryans, P. (2000), "Management development in the public sector - what roles can universities play?", The International Journal of Public Sector Management, Vol. 13 No. 2, pp. 142-152.

\begin{abstract}
About the author
Dr Jennifer Lawlor is a Lecturer in Strategic Management at undergraduate and Master's level at the Dublin Institute of Technology. She has presented a number of conference papers in the USA, UK, and Europe in the area of inter-firm collaboration and co-operation. Her research interests include organisational change, corporate culture, and service design and delivery. Dr Jennifer Lawlor can be contacted at: jennifer.lawlor@dit.ie
\end{abstract}

To purchase reprints of this article please e-mail: reprints@emeraldinsight.com Or visit our web site for further details: www.emeraldinsight.com/reprints 